\title{
ALGORITHM FOR SNOW MONITORING USING REMOTE SENSING DATA
}

\author{
Gordana KAPLAN ${ }^{1, *}$, Ugur AVDAN ${ }^{2}$ \\ ${ }^{1} \mathrm{PhD}$ Candidate, GIS and Remote Sensing, Earth and Space Sciences Institute, Anadolu University, Eskişehir, Turkey \\ ${ }^{2}$ Assistant Professor, Earth and Space Sciences Institute, Anadolu University, Eskişehir, Turkey
}

\begin{abstract}
Snow cover is an important part of the Earth`s climate system so its continuous monitoring is necessary to map snow cover in high resolution. Satellite remote sensing is a science that successfully can monitor land cover and land cover changes. Although indexes such as Normalized Difference Snow Index (NDSI) has quite good accuracy, sometimes topography shadow, water bodies and clouds can be easily misplaced as snow. Using Landsat TM, Landsat +ETM and Landsat TIRS/OLI satellite images, the NDSI was modified for more accurate snow mapping. In this paper, elimination of the misplaced water bodies was made using the high reflectance of the snow in the $0.45-0.52 \mu \mathrm{m}$ wavelength. Afterward, the algorithm was used for estimating snow cover through the years on the one of the highest mountains in Republic of Macedonia. The results from this study shows that the algorithms provide good accuracy than the NDSI alone, totally eliminating the misplaced water bodies, and partly the one caused from topography and clouds. Also, it was noticed that the snow cover in the study area has not been changed drastically through the years. For future studies, the algorithm should be validated on different study areas with different characteristics.
\end{abstract}

Keywords: Remote sensing, Snow monitoring, Landsat, MNDSI

\section{INTRODUCTION}

Land cover is a subject to change through natural cycles and anthropogenic activities as natural resource management, grazing, urbanization, and agriculture [1]. Land use and land cover changes monitoring are an important part of the ecosystem and remote sensing offers great potential in monitoring land cover, land use and land changes. The cryosphere as an integral part of the global climate system plays a significant role in the global climate and in the climate model response to global changes. The cryosphere is defined as the Earth`s surface where water is in solid form, including sea ice, lake ice, river ice, snow cover, glaciers, ice caps, ice sheets, and frozen ground. The monitoring of the cryosphere is essential and needs to be up to date. Snow cover in particular is an important natural resource where hydropower and agriculture constitute two major contributors to the national exchequer. Monitoring of seasonal snow is important to understand the impact of climate change on water availability for development of the country [2]. Also, snow cover is a key component of regional and global climate, and it is crutial to be able to accurateley map and monitor snow cover [3]. Number of researchers and indexes have been developed using remote sensing sensors and data, such as MODIS, Landsat TM, +ETM, OLI/TIRS etc. Normalized Difference Snow Index has been widely used in snow monitoring [4-6], as well as other indexes and ratios [7-9]. The NDSI in some cases is identical as the Normalized Difference Water Index NDWI [10] values. The NDSI in most of the cases uses the bands with reflectance in the green and in the shortwave infrared, while the NDWI can be used in different forms using near infrared. However, both of the indexes successfully maps both snow and water areas, as well as the other low-albedo areas causing some misleads. The complexity and part of the potential mislead during snow monitoring are presented in [3]. For the NDSI a threshold of 0.4 has been suggested [11], as for the water areas a threshold 0 has been suggested which sometimes can make overlap between the snow and the water areas, leading us to false results. 
In this paper, a modification of the NDSI index has been made for successful monitoring of the snow areas, and eliminating water areas and other low-albedo areas. Although there are few developed snow and water indexes, most of them use the relationship between the visible and infrared part of the electromagnetic spectrum. The most frequent used index for snow monitoring is the one using green and near infrared band [2].

$$
N D S I=\frac{\text { Green }-N I R}{\text { Green }+N I R}
$$

NDWI index uses the same bands as NDSI [10]. Modifications of NDWI has been made replacing NIR band with shortwave infrared band (SWIR) [12].

$$
N D W I=\frac{\text { Green }-S W I R}{\text { Green }+S W I R}
$$

As a study area Republic of Macedonia has been selected for its high mountains and presents of snow during the winters. For this study Landsat TM, +ETM and OLI/TIRS satellite images were used.

\section{STUDY AREA AND METHODS}

As a study area some mountains in Republic of Macedonia (Figure 1) have been selected that have high snowfall in winter and are also great winter sport centers. Located in the northwest part of Republic of Macedonia in the border with Kosovo and Albania, Shar Planina or Shar Mountains is one of the biggest and highest mountains in the region. The tourism in this area has big potential. In the winters it is used as a ski center and in the other period it is used for mountain climbing, mountain biking etc. The mountain is covered with snow in winter and beginning of spring, starting from middle November to end of April. Snow monitoring can be of great use in this kind of area. The northwest part of Republic of Macedonia is also rich with water bodies. In this paper, we tried to find a difference between the snow and water body characteristics that will help us to separate the misleading that sometimes the NDSI can create. First of all it was noticed that most of the water areas in this study area have NDSI value higher than 0.4 that classifies them as snow areas. It was also noticed that most of the snow areas have NDSI value higher that 0.75 , but some of the area have values between 0.4 and 0.75 , so a threshold higher than 0.4 cannot be set. For this purpose, the spectral signatures (the difference in the reflectance/emittance characteristics with respect to wavelengths) were retrieved using Erdas IMAGINEs spectral profile tool that extracts the spectral values of a given point. This step will help through the examination of the spectral difference between the snow and water areas (Figure 2). 
Kaplan and Avdan / Anadolu Univ. J. of Sci. and Technology A-Appl. Sci. and Eng. 18 (1) - 2017

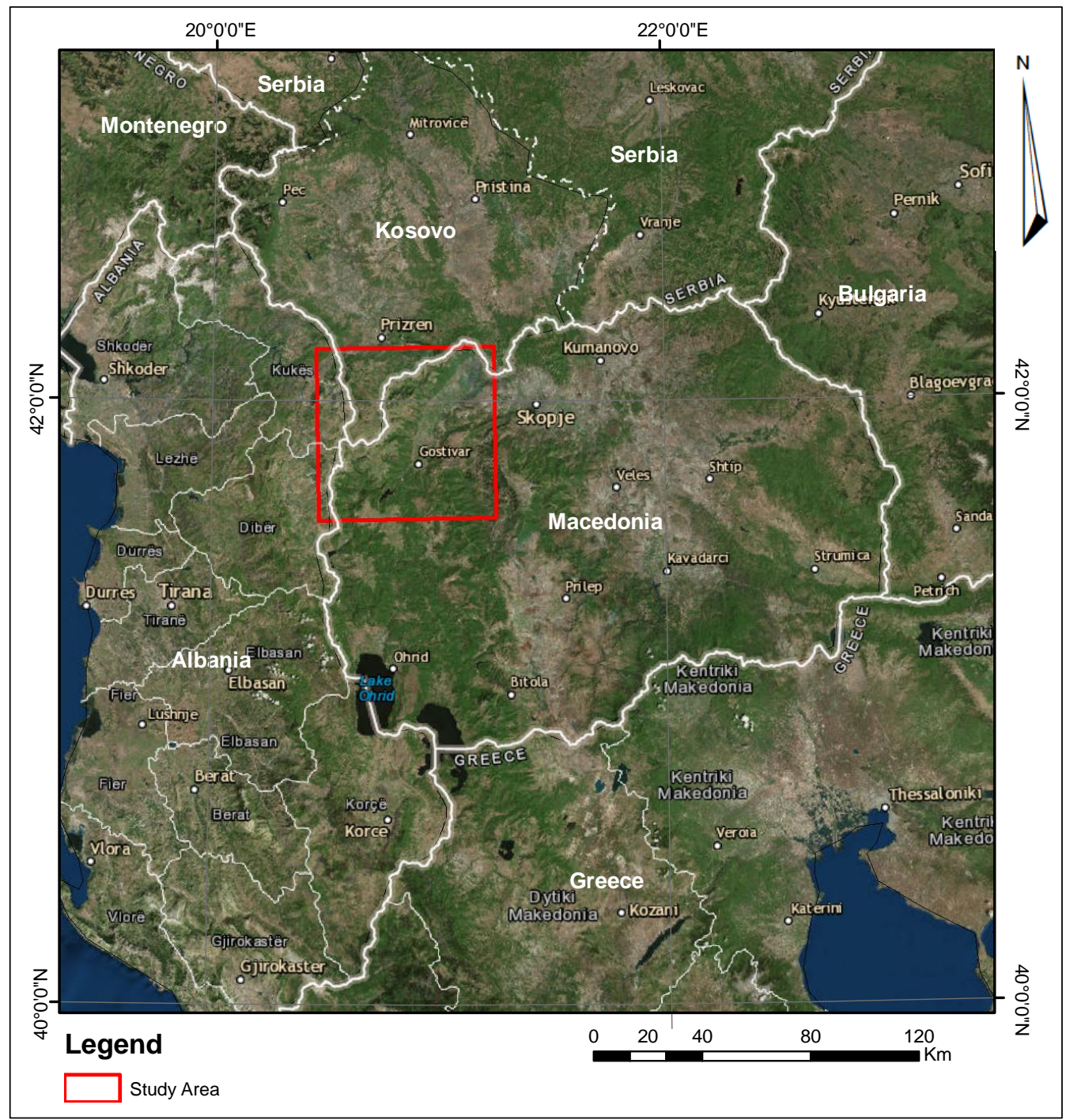

Figure 1. Study area - location of Shar Mountain

From the spectral analysis it can be concluded that the biggest and stable difference between the water and snow spectral signature is in the blue band. The method used in this paper uses NDSI and blue band threshold set from the spectral analysis where it was concluded that in this study area snows lowest value in the blue band is 200 for Landsat 5 and 7, and 12000 for Landsat 8 as shown in the flowchart (figure 3). The blue bands threshold was set differently for Landsat 5 and 7, and Landsat 8 considering their different radiometric resolution (Table 1). Any pixel having a higher value than zero is considered to be snow. 
Kaplan and Avdan / Anadolu Univ. J. of Sci. and Technology A - Appl. Sci. and Eng. 18 (1) - 2017

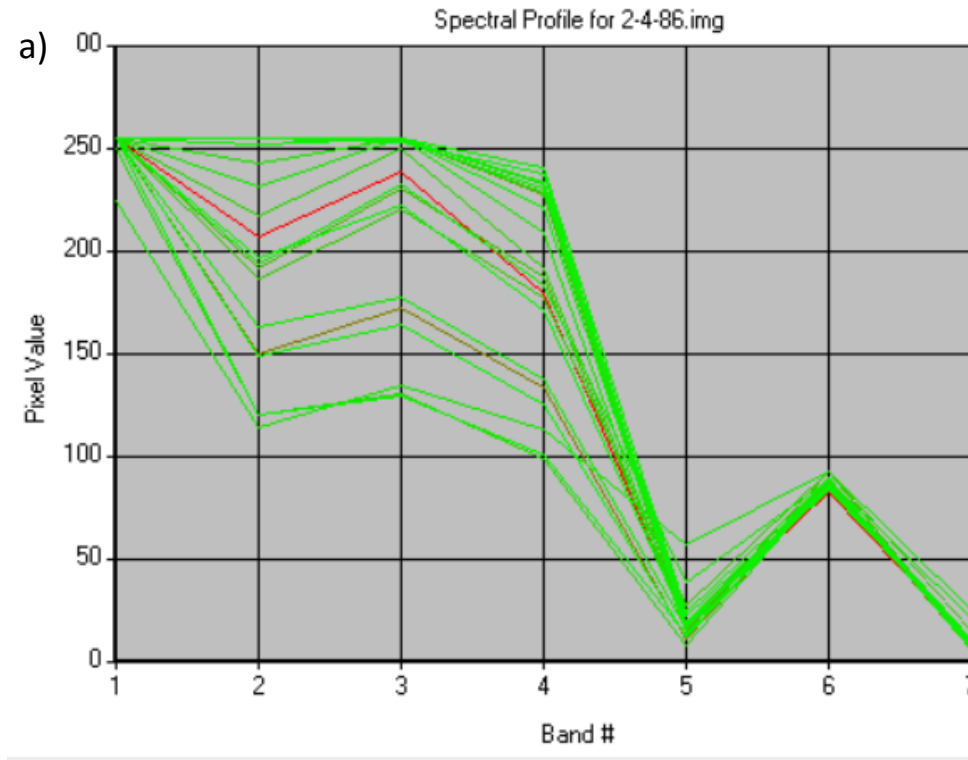

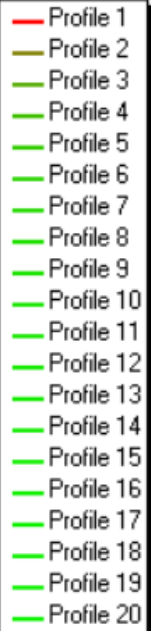

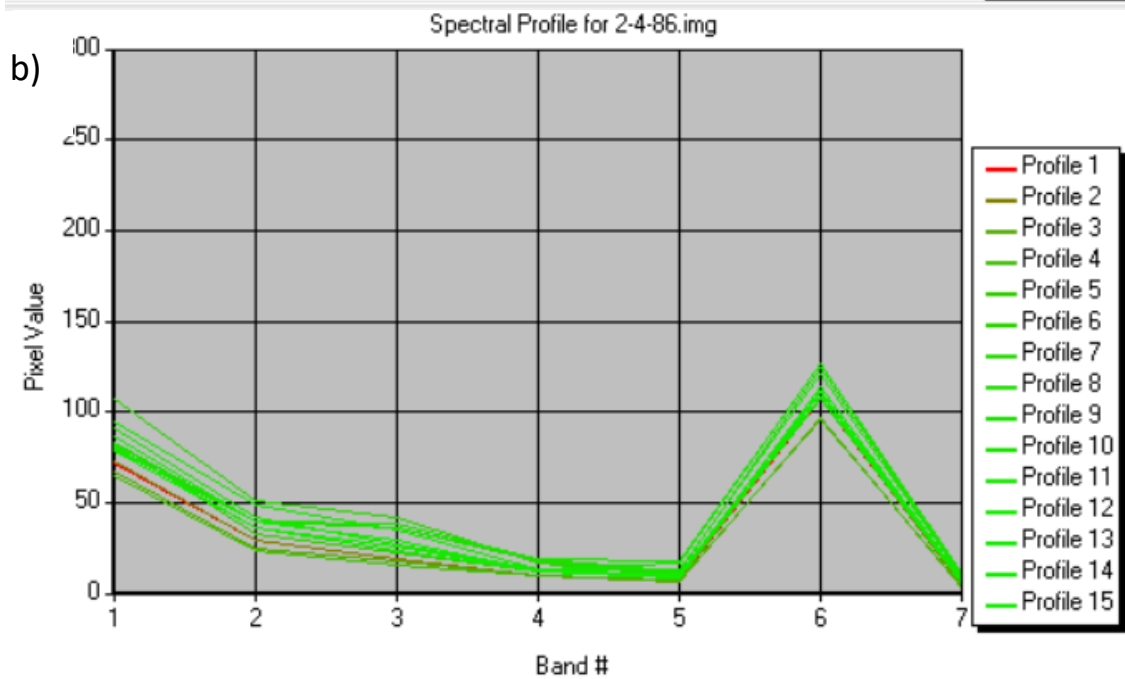

Figure 2. Comparison of snow and water spectral profiles; a) snows spectral profile; b) waters spectral profile

Table 1. Used bands and their characteristics

\begin{tabular}{llll} 
& Landsat 5 $(\mu \mathrm{m})$ & Landsat 7 $(\mu \mathrm{m})$ & Landsat $8(\mu \mathrm{m})$ \\
\hline Blue band & Band 1 $(0.45-0.52)$ & Band 1 $(0.45-0.52)$ & Band 2 (0.45-0.51) \\
Green band & Band 2 $(0.52-0.60)$ & Band 2 $(0.52-0.60)$ & Band 3 $(0.53-0.59)$ \\
SWIR & Band 5 (1.55-1.75) & Band 5 $(1.55-1.75)$ & Band 6 (1.57-1.65) \\
\hline
\end{tabular}




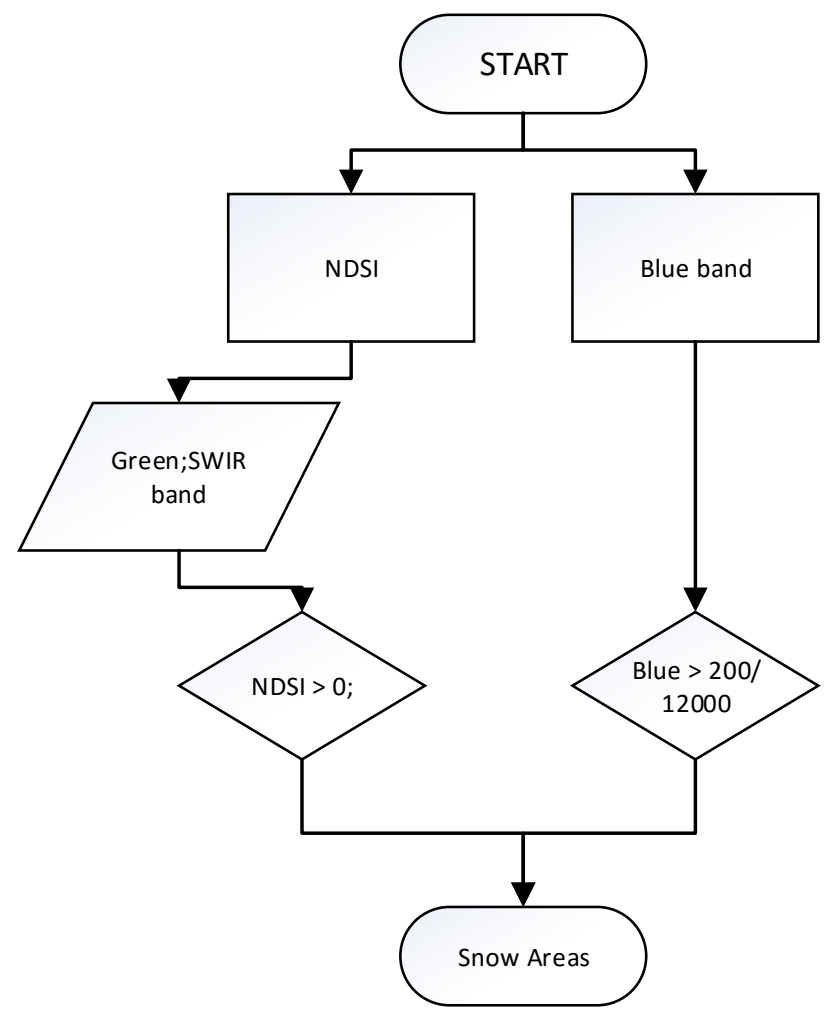

Figure 3. Flowchart

\section{RESULTS AND APPLICATION}

The results from the analysis show that NDSI alone is not successfully extracting snow without misleading. The biggest misleading come from water areas, bare lands and other low albedo valued areas. The NDSI is using the green and SWIR bands and cannot separate some water areas from snow areas. Analyzing the spectral profiles between water and snow areas it was concluded that there is a big difference in the blue band that can be used for separating snow areas. Figure 4 clearly shows the difference between NDSI and algorithm developed in this paper. NDSI cannot separate snow areas from water areas even with threshold of 0.4. As seen on Figure 4-A and 4-D Mavrovo Lakes area is also classified as snow area. But using the algorithm developed in this paper has improved the results with eliminating the water areas and bare lands. The results can be clearly seen on Figure 4 where the Mavrovo Lake is no longer classified as snow area in the MNDSI results. Clearly the algorithm developed in this paper has improved the results from the NDSI. Setting a threshold of 0.4 cannot be useful for any kind of study area which provide the need of new/modified method for extracting snow area. The algorithm developed in this paper has given satisfying results that can separate snow areas from water and bare lands, that sometimes the NDSI misleads.

The algorithm developed in this paper has been applied for snow monitoring in the given study area from 1986 to 2016. Four Landsat images have been used from nearly same period. All of the downloaded images are from middle March and early April. The results are given in figure 5 and table 2 . 
Kaplan and Avdan / Anadolu Univ. J. of Sci. and Technology A-Appl. Sci. and Eng. 18 (1) - 2017

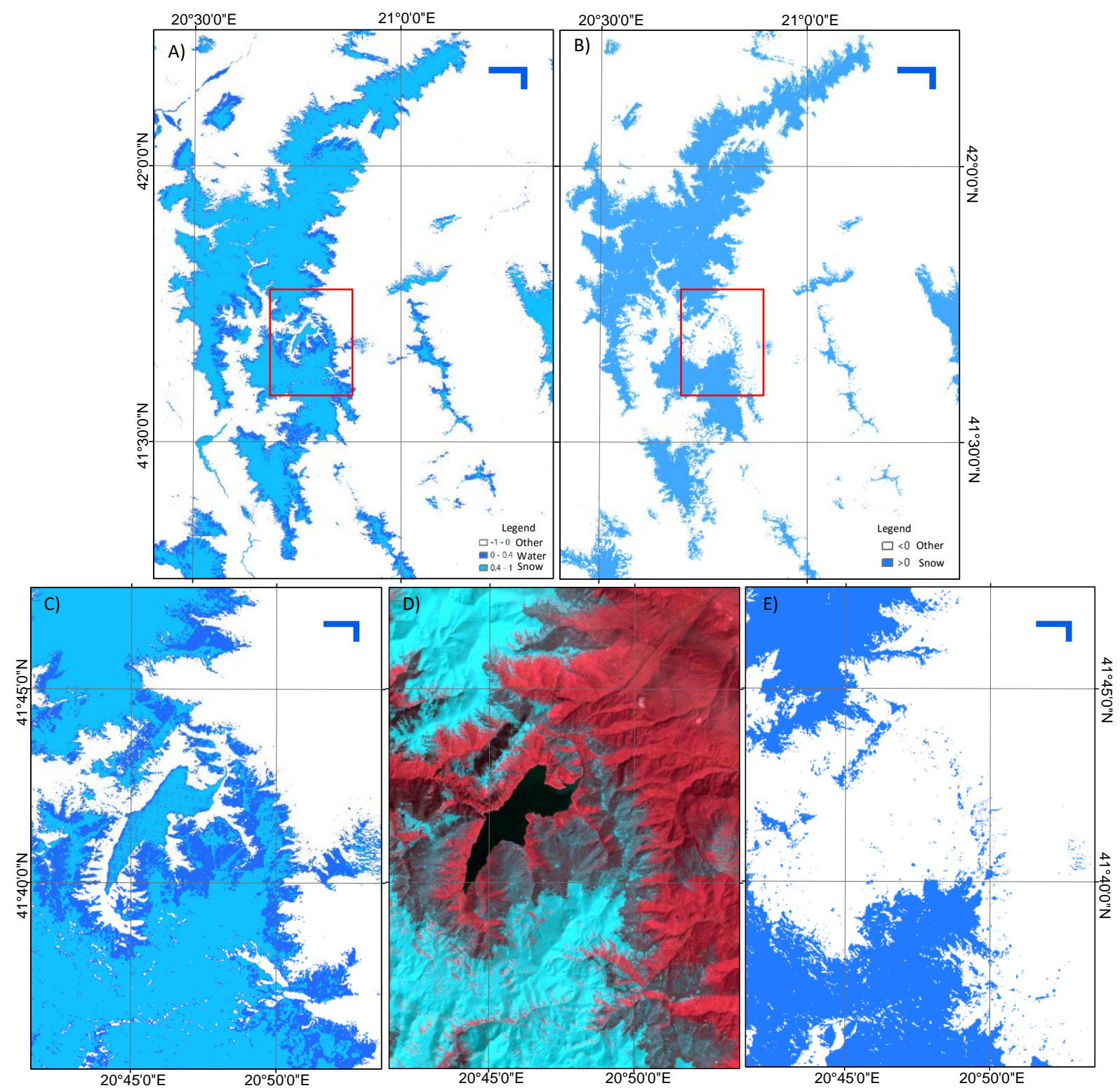

Figure 4. 02 April 1986 Landsat TM; a) NDSI; b) MNDSI; c) NDSI detail; d) RGB 5, 2, 3; e) MNDSI detail. The detail has been focused on Mavro Lake. Values higher than zero represent snow area (blue color)

In Figure 4a, and more detailed in $4 \mathrm{c}$, it can be seen that values lower than zero are represented as other, values from $0-0.4$ are supposed to be water areas and values higher than 0.4 are supposed to be snow area, which is not the case in this study area. From Figure $4 \mathrm{c}$ it can be clearly seen that most of the Mavrovo Lakes area is classified as snow area, or has value higher than 0.4.

Table 2. Details and results from the snow monitoring from 1986 to 2016 using the developed algorithm

\begin{tabular}{ccc} 
Satellite & Date & Snow area $\mathrm{km}^{2}$ \\
\hline Landsat 5 & $02 / 04 / 1986$ & 1611.31 \\
Landsat 7 & $24 / 03 / 2003$ & 2837.07 \\
Landsat 8 & $14 / 03 / 2014$ & 1319.03 \\
Landsat 8 & $19 / 03 / 2016$ & 1807.66 \\
\hline \multicolumn{3}{c}{243}
\end{tabular}


Kaplan and Avdan / Anadolu Univ. J. of Sci. and Technology A-Appl. Sci. and Eng. 18 (1) - 2017
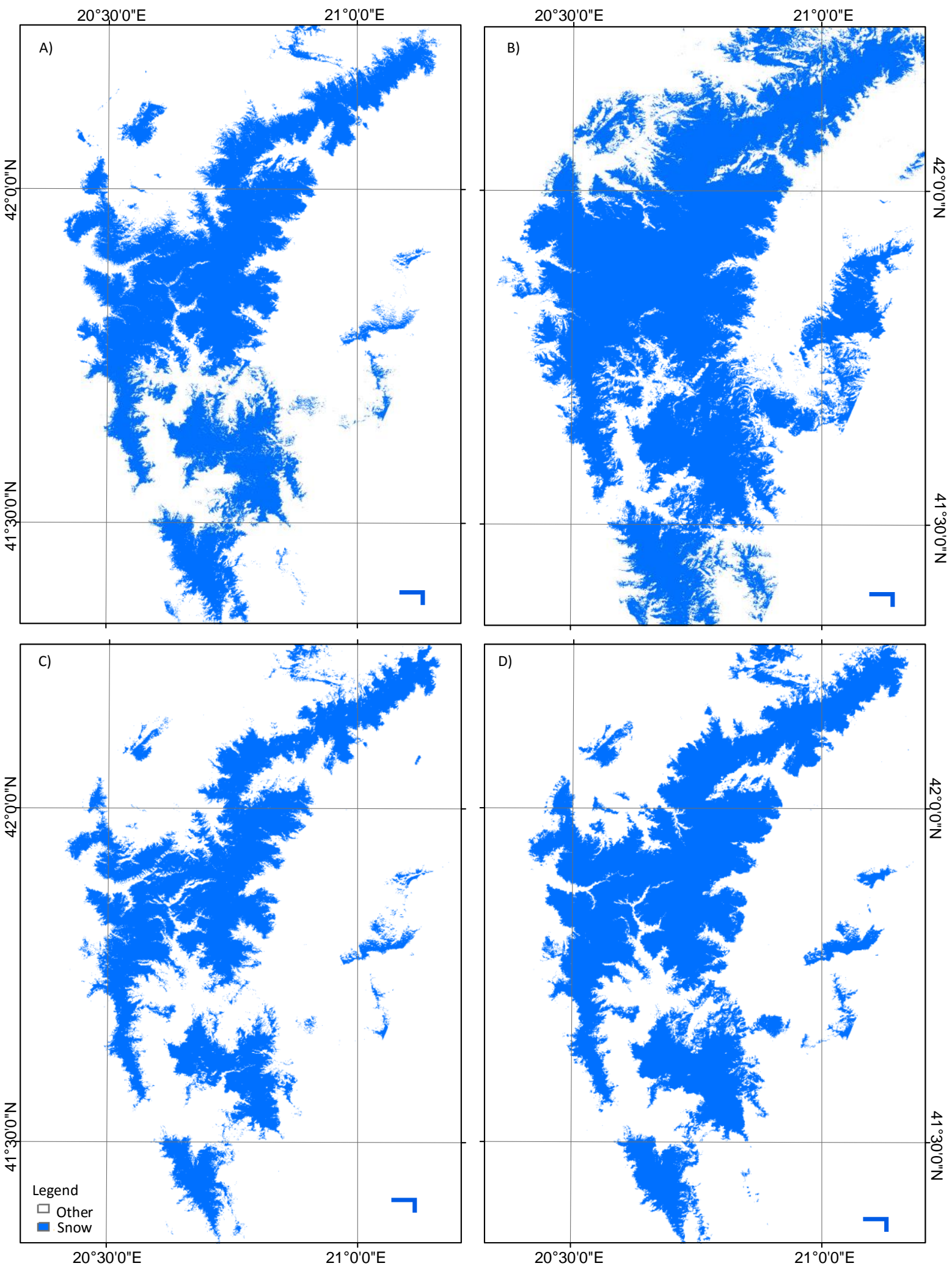

Figure 5. A) 02 April 1986 Landsat 5; B) 24 March 2003 Landsat 7; C) 14 March 2014 Landsat 8; D) 19 March 2016 Landsat 8 
Kaplan and Avdan / Anadolu Univ. J. of Sci. and Technology A-Appl. Sci. and Eng. 18 (1) - 2017

\section{DISCUSSION}

In this paper an attempt for accurately snow retrieving from Landsat satellite images has been made. Using the most common used index for snow monitoring, NDSI, that uses green and SWIR bands, a modification with adding a blue band threshold has been applied. The need for this kind of research comes from the misleading of the NDSI which in most cases are caused by water areas, bare lands and other low albedo valued areas. The index used in this paper proposes using NDSI and setting threshold to the blue band since the snow areas results in high blue-band values and water and bare lands area with low values. The threshold can be set somewhere in the middle or even higher, depending on the study area. For the study area in this paper we have used 200 threshold value for Landsat TM and Landsat +ETM, and 12000 for Landsat OLI/TIRS blue band. This values have been chosen by doing spectral profile analysis. Using the algorithm developed in this paper, the results were improved for more than 90\% with eliminating the water and bare lands areas as seen on Figure 4. The MNDSI has been applied for snow monitoring in one of the highest mountains in Republic of Macedonia, Shar Mountain, and it was concluded that the snow area has not been much different since 1986, but there has been a big snow fall in 2003. The developed algorithm can be of great use in study area with mixture of water bodies and mountainous regions. For future studies, the algorithm should be validated on different study areas with different characteristics with ground measurements or high resolution images.

\section{REFERENCES}

[1] Ustin SL. Remote sensing of environment: State of the science and new directions. Remote Sensing of Natural Resources Management and Environmental Monitoring, 2004.

[2] Gurung DR et al., Monitoring of seasonal snow cover in Bhutan using remote sensing technique. Current Science, 2011. 101(10): p. 1364-1370.

[3] Hall DK, Riggs GA and Salomonson VV. Development of methods for mapping global snow cover using moderate resolution imaging spectroradiometer data. Remote sensing of Environment, 1995. 54(2): p. 127-140.

[4] Butt MJ. Characteristics of snow cover in the Hindukush, Karakoram and Himalaya region using Landsat satellite data. Hydrological Processes, 2012. 26(24): p. 3689-3698.

[5] Butt MJ. Exploitation of Landsat data for snow zonation mapping in the Hindukush, Karakoram and Himalaya $(\mathrm{HKH})$ region of Pakistan. Hydrological Sciences Journal-Journal Des Sciences Hydrologiques, 2013. 58(5): p. 1088-1096.

[6] Choi H. and Bindschadler R. Cloud detection in Landsat imagery of ice sheets using shadow matching technique and automatic normalized difference snow index threshold value decision. Remote Sensing of Environment, 2004. 91(2): p. 237-242.

[7] Stueve KM, et al., Snow-covered Landsat time series stacks improve automated disturbance mapping accuracy in forested landscapes. Remote Sensing of Environment, 2011. 115(12): p. 3203 3219.

[8] Negi HS, et al., Monitoring and evaluation of seasonal snow cover in Kashmir valley using remote sensing, GIS and ancillary data. Journal of Earth System Science, 2009. 118(6): p. 711-720. 
Kaplan and Avdan / Anadolu Univ. J. of Sci. and Technology A-Appl. Sci. and Eng. 18 (1) - 2017

[9] Lan YC, et al., Snow Cover Monitoring by Remote Sensing and Snowmelt Runoff Calculation in the Upper Huanghe River Basin. Chinese Geographical Science, 2002. 12(2): p. 120-125.

[10] McFeeters SK. The use of the normalized difference water index (NDWI) in the delineation of open water features. International Journal of Remote Sensing, 1996. 17(7): p. 1425-1432.

[11] Hao X, Wang $\mathrm{J}$ and $\mathrm{Li} \mathrm{H}$. Evaluation of the NDSI threshold value in mapping snow cover of MODIS - A case study of snow in the Middle Qilian Mountains. Journal of Glaciology and Geocryology, 2008. 30(1): p. 132-138.

[12] Gao BC, NDWI - A normalized difference water index for remote sensing of vegetation liquid water from space. Remote Sensing of Environment, 1996. 58(3): p. 257-266. 